\title{
Public Spots as a Neoliberal Governmental Risk Strategy in Contemporary Turkey
}

\author{
Bahar Aykan \\ Department of Sociology, \\ Marmara University, Istanbul, Turkey \\ aykanbahar@yahoo.com \\ Sanem Güvenç Salgırlı \\ Department of Sociology, \\ Marmara University, Istanbul, Turkey \\ sanemguvenc@gmail.com
}

Doi:10.5901/ajis.2013.v2n8p304

\begin{abstract}
In recent years, Turkish audience has been increasingly exposed to a new media product called 'public spots'. These are less than a minute short clips produced on issues (such as health, security, social solidarity, and environment) that the Turkish state (and its governmental apparatus) finds crucial to 'inform' and 'educate' the public. Whilst the content and scope of these clips are varied, the thread that weaves them is the goal of improving public awareness on potential risks of life. As such, these clips point to a new relationship that the Turkish state aspires to form with the public. In this article, we rely on the literature on neoliberal governmentality, and its core concept, 'indirect governance', to understand the fabric of this relationship. We use three aspects of indirect governance, i.e. 'attribution of responsibility to the individual', 'development of precautionary measures', and 'generalization of population', to discuss the changing nature of state-society relations in contemporary Turkey.
\end{abstract}

Keywords: public sports, state, risk, neoliberal governmentality, Turkey

\section{Introduction}

Public spots are short media clips (around 45 seconds) aired pro bono during commercial breaks on national and local TV channels as well as the radio. They need to be accredited by the RTÜK (Radio and Television Supreme Council) to be named as such and to enjoy the privileges of being exempt from high commercial fees. Whilst most of them are produced by public institutions (that are ministries and directorates working in collaboration with advertising agencies), lately NGOs have also joined this trend.

Ever since the first appearance of public spots in 2008, they have flourished so much so that almost all areas of life have been made into a public spot due to the efforts to 'inform and educate the public'. Even the celebrities are now lining to take part in public spots voluntarily. Virtually everyday Turkish public is exposed to new public spots. Their topics cover a wide array of issues including, but not limited to, hospital services, street children, traffic rules, mugging, efficient energy use, Internet abuse of children, vaccination, promotion of family and social solidarity, occupational accidents and safety, obesity, equality for women, smoking, senior and disabled services, domestic violence, Alzheimer, food safety and hygiene, herbal medicine, child labor, and autism. As such, public spots have been over-abundantly haunting the visual and audial culture of contemporary Turkey. Despite this, there has yet to be a scholarly work on their short but prolific lifespans.

In this article, we aim to fill this gap but we do not specifically engage in analyzing the public spots in and of themselves. Rather, we use them as a heuristic tool in exploring the changing nature of state-society relations, specifically those that are constructed through the mediation of risk in contemporary Turkey. We will particularly navigate the questions of how state positions itself in relation to risks, which aspects of life it sees as both causing and being affected by risks, and which risks it selects to warn individuals to be cautious about. It is in light of these questions that we delve into the public spots. They are crucial in showing how the state deploys itself and the individual according to 
those aspects of life that it considers risky and to whom it attributes the responsibility of taking precaution to avert these risks.

In what follows, we use neoliberal governmentality ${ }^{1}$ as our guiding framework and primarily discuss indirect governance (or governance at a distance) as its core concept when analyzing risk as the newly arising intermediary element in contemporary Turkey's state-society relations. Then, accompanying the analysis of several public spots on health and security aired on national TV, we explore the ways indirect governance works through them. We close by discussing how public spots work as a guideline for responsibilized individuals on approaching risks of life with a precautionary attitude.

\section{Risk, Neoliberal Governmentality, and Indirect Governance}

For nearly three decades, there has been a significant increase in the studies concerning risk, largely owing to Ulrick Beck's 1986 book, Risikogesellshaft. Following its translation into English in 1992 as Risk Society, it induced numerous scholarly debates predominantly remaining within, but not limited to the disciplines of sociology, anthropology, political science, and international relations. Beck (1992), in his work, claimed that late modern societies are in the process of transforming into risk societies. Late modernity, characterized by a "proliferation of frequently incalculable industrial and technological hazards" (Dean, 2007: 65), refers to an era where risks multiply rapidly and thus become inescapable and routinized features of social life. Beck's work has been both celebrated and criticized by many. The latest criticisms, largely drawing upon Foucauldian approaches to risk that can be grouped under the rubric of neoliberal governmentality, place Beck within a realist tradition and argue that any such realist position reduces risks to their quantitative arrangements and assigns them ontological status. In the oncoming discussions we will proceed alongside this particular perspective's conceptualization of risk, which alternatively posits it as a tactic, strategy, technique and/or a form of governance and studies the multiple ways in which risks are calculated, administered, overseen, and taken care of (Joseph, 2012: 14).

Scholars studying risk from the perspective of neoliberal governmentality acknowledge that in contemporary societies, or in today's neoliberal states, risk governance proceeds by indirect rather than direct methods - the latter being associated with governance strategies of welfare states. Among many characteristics that define indirect governance of risk or risk governance at a distance, in this article we will focus on what we consider the three most defining and pivotal of all, i.e. attribution of responsibility to the individual, development of precautionary measures, and generalization of population.

As an example of direct governance, welfare states largely assume the responsibility of their citizen's wellbeing, regulating their lives by foreseeing risks and duly taking preventive measures to avert them. Under neoliberal governmentality, however, neoliberal state's indirect governance gently situates responsibility of managing risks onto the care of the individual herself/himself, cautioning her/him to take measures for her/his wellbeing. Here, risks are defined one by one and techniques of dealing with them are arranged and deployed at the individual level. Depending upon this, it can be said that neoliberal governmentality both individualizes risks and positions individuals accordingly, paving the way to the responsibilization of individuals (Rose, 1999; Dean, 1999; Lemke, 2002; Guthman, 2008). Wearing responsibility brings self-governance along with it. In other words, under neoliberal states risks relate to individual's selfknowledge, self-control, self-improvement (Manzenreiter, 2012: 62) as well as self-empowerment (Guthman, 2009: 102425).

Seeing risks as external impositions on life, welfare state aims to prevent already identified and calculated risks, i.e. it deals with those risks it deems certain. Through direct governance it acts upon those issues it knows of (and have previously established) as risks via selection, classification and hierarchization aimed at determining the high/low probability of the occurrence of their dangers. Yet, whereas welfare state handles already determined risks, neoliberal state concerns itself with their potentiality. Indirect governance strategy of neoliberal state, embracing the principle of precaution, approaches life itself as risky, and as such does not problematize risks as contaminating the purity of life - as was the case in welfare states. Preventive and precautionary measures are different risk management strategies. As

${ }^{1}$ Scholarly literature on neoliberal governmentality includes, but is not limited to, the following themes: immigration, immigrants and refugees (Mitchell, 2006; Andrijasevic and Walters, 2010; Hiemstra, 2010); terror, security and the world after 9/11 (Debrix and Barder, 2009; Tosa, 2009; Dean, 2010); changes in work relations (Hairong, 2003); health and body politics (Guthman and DuPuis, 2006; Guthman, 2009; Manzenreiter, 2012), changes in state and civil society relations (Ferguson and Gupta, 2002; Sharma, 2006), and etc. 
François Ewald (2002: 286) succinctly puts, while preventive principle builds upon "certainty as to the consequences of an action", the notion of precaution concerns a situation in which only a relationship of possibility, eventuality, plausibility, or probability between a cause and its effect can be envisaged. The hypothesis does not concern exactly an unknown cause, but rather a probable or suspected cause... The precautionary hypothesis puts us in the presence of a risk that is neither measurable nor assessable-that is, essentially a nonrisk... Precautionary logic does not cover risk (which is covered by prevention); it applies to what is uncertain that is, to what one can apprehend without being able to assess.

The governance strategy embedded within precautionary principle justifies taking an action on an unforeseen and incalculable future, as it tries to capture uncertainty by domesticating it as risk. It is in this sense that 'nonrisk becomes risk'. This, however, should not yield the conclusion that preventive attitude towards risk is on the process of being replaced by a precautionary one. Rather, as Aradau and Van Munster argue (2007: 102) contemporary risk management strategies involve both preventive and precautionary tactics, where precautionary element stands as an addition to the preventive one. As such, the scope of risk management enlarges by incorporating precautionary measures, which acts on risks viewed as intrinsic to life itself, or remaining nascent in life and thus being unavoidable and too many to calculate.

As neoliberal state cannot possess an extensive knowledge of all the potentiality of risks, it merely proposes certain hypotheses, or certain guidelines to the individuals and asks them to be wary. It is precisely at this point and as a result of such conceptualization that the population expands and generalizes in the face of risks in neoliberal states. Given that the individual is the responsibilized agent, and having an altogether precautionary attitude towards life that requires being alert, wary and on guard perpetually, s/he possesses a double predisposition. S/he could be part of the group to generate risks and also be their victim, which blurs the distinction between the population(s) that causes risks as well as that which is victimized by risks (Aradau and Van Munster, 2007: 107). In contrast to this problematization, in welfare states, even though the population is also classified according to risks, such classification distributes groups according to those subject to risks and those who can generate them, clearly demarcating the boundaries between the two. Under neoliberal governmentality, though, no group is privileged enough to be protected from risks and thus the entire society face the danger of being exposed to them (Lupton, 1999: 94).

These three aspects of indirect governance that we briefly discussed are important to understand the changing nature of state-society relations in contemporary Turkey. Turkish state addresses the population in all its generality, and responsibilizes each individual in the face of risks by providing guidelines, on which precautionary measures to adopt, namely the public spots. Before delving into the details of indirect governance in contemporary Turkey, we need to clarify one point. Even though for the sake of argument we have discussed indirect governance in comparison with and as posing a stark contrast to what we called direct governance, we do not claim that there is a shift from the latter to the former (or that the former replaces the latter). This takes its cue from Foucault's (2007) lectures titled Security, Territory, Population at the Collège de France, where he discussed sovereignty, discipline and biopolitics not as types of power defining three consecutive epochs but rather as separate modalities of power, which could exist side by side. Our aim here is not to make a hasty point by arguing that indirect and direct governance could serve as modalities of power, we simply posit the two as coexisting strategies of governance.

\section{Indirect Governance of Health and Security: Turkey's Public Spots}

Regarding the confines of our article, in this section, we will discuss how indirect governance of risks works in contemporary Turkey by only looking at the public spots on health and security that the Ministry of Health and the Turkish National Police produced. Our argument partially builds upon the literature on neoliberalism, which claims that statesociety relations have drastically changed after the 2000s. Scholars working on this period observe that Turkish state has been withdrawing from areas of education, health, employment and social security. Following the wave of privatizations that began in the 1990s (and have been going on full throttle since the 2000s), Turkish welfare state has begun to evolve into a neoliberal one. Yet, these scholars often evaluate this process as the dissolution and/or pacification of the state. We, on the other hand, alternatively propose that Turkish state is neither dissolving nor being pacified, but it is in the process of restructuring. In other words, the Turkish state has started to disengage gradually from directly interfering into education, health, employment, and social security as has been the case for direct governance. Encouraging individuals towards self-responsibilization, it instead resorts to indirect governance.

Emergence of indirect governance shows itself most acutely on how state manages risk; and the fact that Turkish state has been recently developing policies on potential risks that endanger society is crucial to analyze this new form of governance. For instance, by privatizing health services (such as increasing the number of private health insurances, encouraging the use of private health services instead of public ones, and cutting down the number of public health 
personnel) the state gradually transfers its responsibility on public health to private sector. However, this does not mean that the state renounces its right over individuals' health. It pinpoints potential risks to the wellbeing of the public and calls for each individual to have control over their bodies and to take responsibility for their health. By identifying guiding principles (avoiding smoking and obesity, exercising regularly, eating a healthy diet, and etc.) it expects individuals to obey them and exert control on themselves in due process.

These characteristics of indirect governance are clearly depicted in health-related public spots. Among many issues that the Ministry of Health focuses (obesity, smoking, alternative medicine, hospital services, and etc.) the ones that circulate most are those related to discouraging smoking and cautioning against obesity. These spots call upon individuals to lead a healthy life and encourage them to take precautionary measures, that is, to act preemptively against the probable poor health risks. To put it differently, individuals are urged to guard themselves from the probable occurrence of illnesses (by quitting smoking before getting sick and avoiding the risk of being obese).

In terms of format, there are two kinds of public spots about quitting smoking: one type encourages it through expert knowledge about potential health hazards and the other through first hand success stories of ex-smokers. The first type is pretty much straightforward. It concentrates on lungs and narrates how smoking damages them by filling air pores with tar. These spots use oversimplified language ("smoking affects your health very badly", "smoking damages you with each puff") and utilize metaphors (depicting lungs in the image of sponges and tar in the image of mud) to make it communicable to the general public.

It is rather the second type that displays novel elements concerning the remaking of relations between state and society through risk. One characteristic of indirect governance that we discussed here, i.e. attribution of responsibility to the individual, can be observed vividly in this type of public spots, where individuals narrate their own stories of how they quit smoking. Some public spots show those who had to quit after they develop illnesses related to smoking, such as pulmonary cancer or KOAH. Here, responsibilization works through emphasis on sentiments of regret. People imbued with these fatal diseases express their regret in many ways. One tells, "I was a bit late; I quit after my lungs were gone"; another one, "I would sacrifice anything for a breath, but I am way too late". With a melodramatic music playing in the background, sick ex-smokers are shown in their miserable hospital rooms, attached to oxygen tubes through their nose or throat. As such, they serve to the public eye as regrettable figures responsible for their own anguish, duly expressed with the slogan, "Smoking is regretting".

This second type of public spots also shows ex-smokers who "chose health before its too late". They share their stories with the audience; specifically the reasons that led them to quit smoking and how they succeeded. The first parts of these public spots are shot in black and white, where ex-smokers talk about how they used to be troubled by effects of smoking. They all recurrently mention chest pain, coughing, and shortness of breath as negative effects of smoking, which are coupled with one particular social effect, the foul smell of cigarette smoke. Then, with black and white screen turning into color, ex-smokers pronounce their decision to quit.

Recurrent theme upon which these stories build themselves is the individual's incubating will power through which we observe the shifted responsibility for health. What is shown to the public is not ex-smokers who quit smoking by seeking help through using nicotine patches, medication, placebos for cigarettes or seeking consultation. Instead, they all quit smoking determinately and painlessly as a result of their conscious and decisive move to never smoke again. Hence, the stories do not narrate possible difficulties of the process of quitting. It is rather asserted that will power of the individual is enough and would eventually be triumphant over smoking. Ex-smokers express this through phrases such as, "In my mind I finished it", "I chose health", "I wanted it from the depth of my heart and I succeeded", and etc. Ergo, what is stressed over and over in these public spots as the road to success is the will power of the self-controlling, selfgoverning, and self-motivated (that is to say, responsibilized) individual.

Such individual and a similar success story also encounter us in public spots on obesity. So far, the Ministry of Health has produced three public spots built upon suggestions on how to avoid the risk of being obese. One of them teaches what BMI (body-mass index) is, explains how individuals should calculate their BMI, and asks them to seek medical help if they are above its 'ideal' range. The other encourages exercising at least thirty minutes per day and works with the slogan of "come on, stand up and you too move against obesity", by showing all sorts people walking or running in all kinds of places. And the last one, very similar to those on smoking, is a success story of a woman who used to be overweight, but lost forty-five kilos in one and a half years by walking, eating less and being more dynamic.

It is very clear how the public spot on BMI responsibilizes individuals. It does so by providing information on BMl's standard procedure. Then it leaves the decision to individuals to see whether they are overweight or not; and if they are, the burden of seeking medical help also befalls upon them. The second one cautions individuals against the 'great risk' of obesity, 'the most important threat of our era', by pointing out how unhealthy diet and sedentary life leads to it. It 
directly calls individuals to exercise regularly everyday but leaves them the choice of how to do it. The spot shows all kinds of people across Turkey (young, old, man, woman, overweight, thin, fit) walking or running in their neighborhoods, in parks, in forests, on beaches, over bridges, on streets, in historical sites, and etc. As such, it suggests walking or running as the easiest and most convenient form of exercise that can be done by everyone, everywhere and at any time of the day. Same emphasis on walking as a form of exercise can also be found in the success story of a once overweight woman, who lost weight by exercising and reducing the size of her portions. In the public spot, she repeatedly stresses her self-motivation to lose weight, explaining how she did this on her own without receiving any professional help. She tells us that what one needs is neither money, nor expensive gyms or beauty centers. "Will power and perseverance" is more than enough to successfully lose weight.

One reason why walking and running are chosen as the forms of exercise in these public spots is that they can be done literally by everyone. That is to say, since everyone is seen under the risk of being obese, no one could (and should) escape taking precautionary measures against the 'threat' of obesity. To put it differently, one does not necessarily be overweight in order to be cautious. Because obesity is constructed as a risk that can seize everyone, regardless of age, gender and class, precautionary measures against it inevitably serves to generalize the population. How the once-overweight woman had lost weight has an all-inclusive appeal in the sense that it addresses each individual in society without discriminating age, gender and / or class. Also, in the second public spot, the fact that there are such diverse locations and people from all spectrums of social life who are shown walking or running, again, generalizes the population.

Generalization of population, although it works through a different mechanism, is also prevalent in the public spots on security produced by the Turkish National Police (TNP). First it needs to be mentioned that the TNP produces as much public spots as the Ministry of Health. They cover a wide range of topics on security warning against theft, fraud, mugging, Internet abuse of children, hackers, smuggling, bomb-threat and cautioning individuals to obey the traffic rules (drunk driving, running a red light, speeding). Among these, we would like to concentrate on the ones on mugging and Internet abuse of children.

The first one starts with a woman walking on a crowded street. A man in his late twenties (no distinctive features) slowly approaches her, snatches her handbag and attempts to run. People walking on the street block his way by immediately surrounding him. Standing with a gutsy and gallant pose and wearing a proud expression on their faces, each individual in the crowd put on a police hat. Seeing the determination of the crowd, the young man apologetically returns the handbag to the woman. The spot ends with the slogan of "anyone who has conscience is a policeman".

Whilst anyone can be a policeman, anyone can also be a criminal. The second public spot, the one on Internet abuse of children, pictures a calm upper middle class suburban neighborhood in the middle of the night. The camera goes inside a cozy house and shows a young mother reading a magazine in the living room, and her twelve years old daughter lying down on her bed and chatting on the Internet. As the young girl thinks that she is chatting with a boy her age, we the audience, hearing his voice, realize that he is rather an adult posing as a child (and most probably a child molester). Right after the man with a deep and perverted voice asks the girl if she has a camera, and the girl writes him to wait, out of nowhere we hear sirens. Mom and the girl rush to the window and see a bunch of police cars surrounding the house next door. As the police shouts "Surrender, immediately come out!", we see stereotypes of criminals leaving the house one after another through the front door: a 'terrorist', a prostitute, a cross-dresser, a thief, and a gambler. But that's not all. The policeman further hails, "Come out!" and then we see ordinary men, not stereotypical criminals, appear on the front door. Noticeably, these men are no different than those who transformed into policeman in the previous public spot on mugging. As they are being handcuffed one by one, the spot concludes with a warning: "A lot a people connected to various crimes may enter our homes via Internet, specifically victimizing 'our' children in due process: Please be cautious and protective!"

These public spots on security responsibilize individuals for safeguarding their environment and for acting preemptively to minimize any potential crime risks that can come from anyone, anywhere, and anytime. Being aware of one's surrounding, staying constantly on alert, and being wary and suspicious of everyone becomes the precautionary duty of the responsibilized individual. At first glance, the security-related public spots seem to play on the figure of the policeman (whom everyone becomes one, and who forces the criminals to come out of the house) highlighting his preventive role in fighting crimes. However, a closer reading reveals that what is suggested here is to approach crimes through precautionary measures rather than preventive ones. The fact that both the young mugger and the ordinary men that come out of the house have no stereotypical features of a 'criminal', attests to the uncertainty concerning how, where and by whom crimes might be committed. It is specifically as a result of such uncertainty surrounding the crimes that everyone (the mother, the individuals walking on the street, and thus the public in general) needs to be wary of anyone, 
all the time.

We have been arguing that indirect governance, when confronted with risks, responsibilizes individuals for taking precautionary measures and duly generalizes the population. This does not, however, mean that generalization works similarly on various distinct occasions and responsibilizes individuals in the same way. A comparison between healthrelated public spots and those on security reveals multiple ways in which we can observe the plurality of these mechanisms. Whereas public spots on health address everyone, those on security address anyone. The former asks each individual to consider herself / himself as being part of everyone, notice risks as everyone else does, and take precautions by responsibilizing herself / himself in the face of risks just like everyone else. The latter, those on security, also addresses a totality / population. They, however, ask individuals to see that anyone could pose a threat, and as such responsibilizes them to be cautious about each single individual and protect both themselves and others from anyone. And it could be surmised easily that if anyone could pose a threat, then the individual herself/himself could also be one of anyone.

It should be noticed that regardless of whether the population is generalized as everyone or anyone, the risks are personified in one way or another. In the former, they are embedded within the individual, and s/he begets them. The sole fact that will power is seen as the road to success in health-related public spots attests to this. In other words, what is posed as necessary and sufficient condition of overcoming the risk of obesity as well as quitting smoking is the sheer will power inherent in the individual. Therefore, everyone should individually responsibilize oneself and take precautionary measures against risks. In security-related public spots, on the other hand, risks are once again personified, but this time in the form of an external other. The threat to one's security comes from an outsider portrayed as a mugger on the street or a disguised child molester. In this respect, because anyone is a potential threat to the security of everyone, the responsibilized individual not only has to be cautious about anyone (regardless of whether or not they fit to the conventional criminal stereotypes) but also needs to prevent crimes and protect their loved ones.

\section{Conclusion}

Further elaboration and research is needed to deduce whether or not these two forms of responsibilization (responsibilization of individuals for protecting their own self against personal risks and their responsibilization for protecting others from external risks) merge within a single individual and/or converge in a novel subjectivity. Already within the scholarly literature on neoliberal governmentality, debates circulating around the concept of good citizen(ship) have been pointing towards a similar problematization in an attempt to understand the contemporary state-society relationships. The good citizen is conclusively defined as a responsibilized individual when confronted with risks (Lupton, 2006; Manzenreiter, 2012). Whether that responsibilization is for personal or external risks (or both), however, is open to discussion. It is largely due to the fact that any such discussion would be a mere speculation unless it is grounded within a given time and place. Besides, neoliberal governmentality works with the principle of indirect governance that is flexible in and of itself. Accordingly, it escapes being defined generically. Responsibilization of individuals is also contextspecific given that under neoliberal governmentality, the aspects of life that are considered risky will always remain ambiguous. In this respect, any definition of good citizen(ship) would need careful contextualization within specific locales.

When we look at the Turkish context, we see that state-society relations have been increasingly defined through indirect governance of risks. Instead of linearly directing individuals towards certain behavioral patterns, the Turkish state has come to designate guidelines for appropriate ways of living via public spots without directly forcing individuals to comply with them. Accordingly, whilst the Turkish state (and its governmental apparatus) provides guidance through public spots, it is the self-motivated individuals rather than the state that is to be hold responsible for dealing with risks. These self-motivated individuals are expected to enter into a precautionary relationship with presumed risks (obesity, smoking, mugging and Internet abuse of children) that are not necessarily pre-calculated. It is because of this vagueness and because life itself poses various potential threats to the self-motivated and responsibilized individual, s/he is expected to approach all aspects of life with a precautionary attitude. In the face of these 'life-threatening' risks, public spots function not only as guidelines on how to approach them, but they also keep the individual in a constant state of alertness when dwelling within life itself. As life is as unpredictable as it is and burgeoning with prolific and indeterminate risks, it is hardly possible for any individual to remain immune to risks of life. It is such unpredictability that generalizes the population as being both the subject and the object of risks under neoliberal governmentality. Turkish state, via public spots, follows a similar mentality when it resorts to call its audience as general and as indeterminate as public. 


\section{References}

Andrijasevic, R. \& Walters, W. (2010). The International Organization for Migration and the international government of borders. Environment and Planning D: Society and Space, 28(6), 977-999.

Aradau, C. \& Van Munster, R. (2007). Governing Terrorism through Risk: Taking Precautions, (un)Knowing the Future. European Journal of International Relations, 13, 89-114.

Beck, U. (1992). Risk Society -Towards a New Modernity. London: Sage.

Dean, M. (1999). Governmentality: Power and Rule in Modern Society. California: Sage Publications.

Dean, M. (2007). Governing Societies. Berkshire: Open University Press.

Dean, M. (2010). Power at the heart of the present: Exception, risk and sovereignty. European Journal of Cultural Studies, 13(4), 459475.

Debrix, F. \& Barder, A. D. (2009). Nothing to Fear but Fear: Governmentality and the Biopolitical Production of Terror. International Political Sociology, 3, 398-41.

Ewald, F. (2002). The Return of Descartes's Malicious Demon: An Outline of a Philosophy of Precaution. In T. Baker \& J. Simon (Eds.), Embracing Risk - The Changing Culture of Insurance and Responsibility (pp. 273-301). Chicago: The University of Chicago Press.

Ferguson, J. \& Gupta, A. (2002). Spatializing States: Toward an ethnography of Neoliberal Governmentality. American Ethnologist, 29(4), 981-1002.

Foucault, M. (2007). Security, Territory, Population - Lectures at Collège de France, 1977-1978, New York: Palgrave Macmillan.

Guthman, J. (2008). Neoliberalism and the Making of Food Politics in California. Geoforum, 39, 1171-1183.

Guthman, J. (2009). Teaching the Politics of Obesity: Insights into Neoliberal Embodiment and Contemporary Biopolitics. Antipode, 41(5), 1110-1133.

Guthman, J. \& DuPuis, E. M. (2006). Embodying Neoliberalism: Economy, Culture, and the Politics of Fat. Environment and Planning D: Society and Space, 24(3), 427-448.

Hairong, Y. (2003). Neoliberal Governmentality and Neohumanism: Organizing Suzhi/Value Flow through Labor Recruitment Networks. Cultural Anthropology, 18(4), 493-523.

Hiemstra, N. (2010). Immigrant 'Illegality' as Neoliberal Governmentality in Leadville, Colorado. Antipode, 42(1), 74-102.

Joseph, J. (2012). The Social in the Global: Social Theory, Governmentality and Global Politics, Cambridge: Cambridge University Press.

Lemke, T. (2002). Foucault, Governmentality, and Critique. Rethinking Marxism, 14(3), 49-64.

Lupton, D. (1999). Risk. London: Routledge.

Lupton, D. (2006). Sociology and Risk. In G. Mythen \& S. Walklate (Eds.), Beyond the Risk Society: Critical Reflections on Risk and Human Security (pp. 11-24). Berkshire: Open University Press.

Manzenreiter, W. (2012). Monitoring Health and the Body: Anthropometry, Lifestyle Risks, and the Japanese Obesity Crisis. The Journal of Japanese Studies, 38(1), 55-84.

Mitchell, K. (2006). Neoliberal Governmentality in the European Union: education, training, and technologies of citizenship. Environment and Planning D: Society and Space, 24, 389-407.

Rose, N. (1999). Powers of Freedom: Reframing Political Thought. Cambridge: Cambridge University Press.

Sharma, A. (2006). Crossbreeding Institutions, Breeding Struggle: Women's Empowerment, Neoliberal Governmentality, and State (Re)Formation in India. Cultural Anthropology, 21(1), 60-95.

Tosa, H. (2009). Anarchical Governance: Neoliberal Governmentality in Resonance with the State of Exception. International Political Sociology, 3, 414-430. 